\title{
O ARGUMENTO DAS CAPACIDADES INSTITUCIONAIS DO PODER JUDICIÁRIO E A CONSTRUÇÃO DE UMA ORDEM JURÍDICA JUSTA E TRANSDISCIPLINAR: POSSIBILIDADES
}

\author{
Artenira da Silva e Silva* \\ Letícia Moreira De Martini*
}

\section{RESUMO}

Este artigo tem como objetivo a análise do argumento das capacidades institucionais do poder Judiciário, seus limites e possibilidades na compatibilização de uma ordem jurídica justa e transdisciplinar. Pretende-se demonstrar que o desenvolvimento do constitucionalismo contemporâneo, embora impulsione o protagonismo judicial, não sustenta a proliferação de juízos decisionistas. O ativismo judicial, justificado através das omissões estatais, possibilita a abertura frente às capacidades institucionais, as quais demandam um equilíbrio entre o grau de discricionariedade administrativa a ser preservado, e a observância aos direitos fundamentais. Utilizou-se como metodologia o levantamento bibliográfico.

Palavras-chave: capacidades institucionais. Poder judiciário. Ordem jurídica justa e transdisciplinar. Ativismo. Direitos fundamentais.

\section{THE INSTITUTIONAL CAPACITIES ARGUMENT OF JUDICIARY POWER AND THE CONSTRUCTION OF A FAIR AND TRANSDISCIPLINARY LEGAL ORDER: POSSIBILITIES}

\begin{abstract}
This article aims to analyze the institutional capacities argument of Judiciary power, its limits and possibilities in compatibilization of a legal order, being fair and transdisciplinary. It is intended to demonstrate that even though the development of contemporary constitutionalism propels the legal protagonist, it does not sustain the proliferation of decisionist judgements. The judicial activism, justified through the omission of state companies, enables the aperture in face of the institutional capacities, which demands a balance between the degree of administrative discretion to be preserved and the compliance to fundamental rights. It was used, as methodology, a bibliographic survey.
\end{abstract}

\footnotetext{
* É pós-doutoranda em Direitos Humanos na Universidade Federal do Pará (2019). É pós-doutora em Psicologia e Educação pela Universidade do Porto- Portugal (2014). Graduada em Psicologia pela Pontifícia Universidade Católica de São Paulo, Mestre em Saúde e Ambiente pela Universidade Federal do Maranhão (2000) e Doutora em Saúde Coletiva pela Universidade Federal da Bahia (2005). Atualmente é docente e pesquisadora associada da Universidade Federal do Maranhão e consultora em violência doméstica e proteção de direitos infantojuvenis. Atua predominantemente do Programa de Pós-graduação de Direito e Instituições do Sistema de Justiça da UFMA. E-mail: artenirassilva@ @otmail.com.

* Mestranda em Direito e Instituições do Sistema de Justiça pela Universidade Federal do Maranhão - UFMA. Pós-Graduada em Direito e Processo do Trabalho pela Universidade Estácio de Sá - UNESA. Graduada em Direito pela Universidade Federal do Maranhão - UFMA. Técnica de Gestão Administrativa (Advogada) da Assembleia Legislativa do Estado do Maranhão. E-mail: leticiademartini @hotmail.com.
} 
Key words: institutional capacities. Judicial power. Fair and transdisciplinary legal order. Activism. Fundamental rights.

\section{INTRODUÇÃO}

Este artigo visa analisar as limitações impostas pelo argumento das capacidades institucionais do poder Judiciário, frente às possibilidades de construção de uma ordem jurídica justa e transdisciplinar.

Para tanto, inicia-se a abordagem acerca do cenário propulsor do constitucionalismo contemporâneo pós-1988, o qual, mediante a agitação democrática e os discursos de valoração dos direitos fundamentais, proporcionou um novo conceito de jurisdição constitucional, cuja hermenêutica abriu-se ao leque de princípios a serem aplicados pelo julgador em prol do enfoque à cidadania (BURGOS; SALLES; VIANNA, 2006; RAMOS NETO, 2009; STRECK, 2017; TRINDADE, 2012).

Nessa busca de concretização máxima dos comandos constitucionais, o Judiciário passa a atuar como protagonista, a fim de que a sociedade tenha assegurada a garantia de cumprimento efetivo das ações públicas previstas no texto constitucional. Passa-se a falar então acerca do perigo da ausência de limites para a discricionariedade e criacionismo judicial, desembocando na argumentação em torno de um ativismo que se fundamenta na necessidade de utilização de critérios metajurídicos para fundamentar "casos difíceis", os quais demandam um esforço interpretativo que não se resolve com o formalismo das leis.

A análise culmina na discussão sobre o enfrentamento do dualismo existente entre a discricionariedade administrativa e o argumento das capacidades institucionais do Judiciário, bem como as reais possibilidades de sopesamento e estabelecimento de um equilíbrio efetivo.

Em verdade, torna-se necessária a percepção de que o juiz, enquanto ator social, inserido num mundo fático e de potencialidades abrangentes, passa a contemplar a valoração de suas decisões mediante a utilização de parâmetros justos e capazes de demonstrar que a capacidade institucional não se encontra engessada a uma única esfera de atuação, permitindo uma atuação dinâmica, voltada ao cumprimento da função social da jurisdição, e, por conseguinte, favorecendo uma atuação judicial transdisciplinar. 
Para o desenvolvimento deste artigo, utilizou-se o método de pesquisa bibliográfico, consistente em levantamento realizado através de referencial teórico pertinente e capaz de fundamentar os assuntos abordados.

\section{CONSTITUCIONALISMO PÓS-1988: A TRAJETÓRIA DO PROTAGONISMO JUDICIAL}

A regulação judicial do cotidiano tem suas origens pautadas nas transformações e necessidades sociais recriadas ao longo da história dos conflitos humanos. Os crimes contra a humanidade, cometidos durante a Segunda Guerra Mundial, ensejaram a latente invocação por uma arqueologia de princípios voltada a uma afirmação desses direitos e sua garantia a nível constitucional.

As novas constituições insurgidas no cenário pós-guerra vieram, portanto, com esse viés protetor, que encontraria no Estado de bem-estar social o fundamento de consolidação do núcleo dogmático almejado. Nesta linha, "o chamado constitucionalismo democrático reclamava, portanto, um Judiciário dotado da capacidade de exercer jurisdição sobre a legislação produzida pelo poder soberano" (BURGOS; SALLES; VIANNA, 2006, p. 2).

Com a ascensão dos Estados Constitucionais de Direito, o constitucionalismo ganha fôlego no desenho institucional global, exigindo um novo conceito de jurisdição, voltada à concretização dos direitos fundamentais e à preservação do regime democrático, as quais validaram a necessidade de uma teoria do direito que lhes desse suporte (TRINDADE, 2012, p. 96-97). Para Ramos Neto (2009, p. 1), “a Constituição passa a ser reinventada pela jurisdição constitucional, dada a dimensão política e jurídica que assumiu e os novos contornos que passou a apresentar pela ópera daquela jurisdição".

O constitucionalismo encontrou seu suporte na máxima efetividade imposta aos poderes constituídos na realização das normas reveladoras de atitudes estatais. Nesse aporte, coube ao Judiciário, enquanto terceiro poder imbuído de zelar pela soberania constitucional, o controle da atuação concreta dos demais poderes, possibilitando, segundo Streck (2017, p. 69), a concepção de um constitucionalismo "como um movimento teórico-jurídico-político em que se busca limitar o exercício do poder a partir da concepção de mecanismos aptos a gerar e garantir o exercício da cidadania”. 
Este movimento de aproximação entre direito e moral proporcionou a paulatina substituição da hegemonia do Poder Legislativo pelo Judiciário, embasado por um "controle de constitucionalidade das leis mais intenso, pela normatividade dos princípios, além de uma preocupação mais acentuada com a efetiva proteção e concretização dos direitos fundamentais" (OLIVEIRA, 2014, p. 59).

Contudo, o grande paradoxo na adoção do constitucionalismo no cenário brasileiro deu-se em razão da crise do "Welfare State", movimentada pelos regimes autoritários que figuravam no cenário político, pela emergência e pelas intervenções neoliberais, cujas reformas minam os direitos sociais e provocam a retração da vida sindical e associativa. Novamente, emerge uma sociedade "sem Estado, sem fé, sem partidos e sindicatos", cujas expectativas de direitos acabam se voltando ao Poder Judiciário, "o muro das lamentações do mundo moderno" (BURGOS, SALLES, VIANNA, 2006, p. 3).

Nesse cenário, a Constituição de 1988 incumbiu-se de eliminar o autoritarismo e viés antidemocrático que cingiam em torno da vida social e política à época, reestruturando os direitos civis da cidadania, recriando as instituições do sistema de justiça, como o Ministério Público, consagrando mecanismos de defesa dos direitos coletivos, como as ações civis públicas, ampliando o tema de acesso à justiça e admitindo a sociedade civil organizada como uma das intérpretes da Constituição (BURGOS, SALLES, VIANNA, 2006, p. 5).

O texto constitucional de 1988 representou muito mais do que a inauguração de uma nova ordem jurídica, de modo que a sua substância revela uma ruptura com os padrões vigentes no direito brasileiro, reconfigurando os compromissos firmados entre sociedade e Estado, redefinindo a democracia e consolidando os direitos fundamentais como imanentes à atuação do Poder Judiciário ${ }^{1}$ (TRINDADE, 2012, p. 114).

Essa envergadura constitucional de proteção a direitos, gradualmente propiciou a formação de uma nova cultura jurídica, através da coautoria do exercício das funções

\footnotetext{
${ }^{1}$ Nesse contexto, surge a ideia de um neoconstitucionalismo, que viria com o propósito de superar um antigo constitucionalismo de feições liberais, que já não se mostrava eficiente em meio às transições sofridas. A esta nomenclatura, Lenio Streck invoca sua crítica, afirmando não se tratar de um novo modelo que rompe com o constitucionalismo precedente, mas que lhe dá continuidade e proporciona a transição para novas conquistas, sendo preferível a adoção da terminologia prescrita como "constitucionalismo contemporâneo": "[...] pode-se dizer que o Constitucionalismo Contemporâneo representa um redirecionamento na práxis político-jurídica que se dá em dois níveis: no plano da teoria do Estado e da Constituição, com o advento do Estado Democrático de Direito; e, no plano da Teoria do Direito, no interior da qual se dá a reformulação da teoria das fontes (a supremacia da lei cede lugar à onipresença da Constituição); na teoria da norma (devido à normatividade dos princípios) e na teoria da interpretação (que, nos termos que proponho, representa uma blindagem às discricionariedades e ativismos)" (2017, p. 68-69).
} 
institucionais primárias do Estado com o Judiciário, transformando-o em um dos protagonistas na rede de persecução dos direitos sociais, no manto de garantias das classes vulneráveis, e incrementando as demandas que viriam atreladas sob o fundamento do acesso à justiça prescrito no art. $5^{\circ}$, inciso XXXV, da Carta de $1988^{2}$.

De fato, com a promulgação da Constituição Federal de 1988, denota-se um levante de reestruturação do Poder Judiciário, conferindo-lhe maior visibilidade no cenário orgânico do país, como se pode aferir através da autonomia financeira que the foi concedida, permitindo-lhe a participação direta na elaboração do seu orçamento (art. 99) ${ }^{3}$. Também passou a ser de sua competência prover os cargos de juiz que compõem o seu quadro (art. 96, I, “c”) ${ }^{4}$, possibilitando-lhe maior grau de liberdade e independência funcional.

O modelo de valoração dos direitos fundamentais, adotado na Constituição de 1988 auxiliou na configuração do Judiciário como revelador da justiça, expandindo seu campo de atuação para outros âmbitos e permitindo dar ao ordenamento jurídico o efeito integrador descrito como princípio da hermenêutica constitucional. Segundo Ribeiro (2013, p. 14), “o desempenho do Poder Judiciário, em um Estado Constitucional democrata, é o de apostilar a Constituição e as leis, protegendo direitos e asseverando o acatamento ao ordenamento jurídico".

Concomitantemente, a complexidade das relações sociais, aliada ao extremo caráter programático das normas constitucionais, levou progressivamente o Judiciário a ocupar as lacunas que o poder político não se mostrava capaz de preencher. Os novos direitos reclamavam proteção, e para que não fossem alçados ao patamar da inefetividade, perpetrada pelo possível fracasso constitucional, o Judiciário passou a assumir a postura paternalista que

\footnotetext{
${ }^{2}$ Art. $5^{\circ}$ Todos são iguais perante a lei, sem distinção de qualquer natureza, garantindo-se aos brasileiros e aos estrangeiros residentes no País a inviolabilidade do direito à vida, à liberdade, à igualdade, à segurança e à propriedade, nos termos seguintes:

$[\ldots]$

XXXV - a lei não excluirá da apreciação do Poder Judiciário lesão ou ameaça a direito.

${ }^{3}$ Art. 99. Ao Poder Judiciário é assegurada autonomia administrativa e financeira.

$\S 1^{\circ}$ Os tribunais elaborarão suas propostas orçamentárias dentro dos limites estipulados conjuntamente com os demais Poderes na lei de diretrizes orçamentárias.

$\S 2^{\circ} \mathrm{O}$ encaminhamento da proposta, ouvidos os outros tribunais interessados, compete:

I - no âmbito da União, aos Presidentes do Supremo Tribunal Federal e dos Tribunais Superiores, com a aprovação dos respectivos tribunais;

II - no âmbito dos Estados e no do Distrito Federal e Territórios, aos Presidentes dos Tribunais de Justiça, com a aprovação dos respectivos tribunais.

${ }^{4}$ Art. 96. Compete privativamente:

I - aos tribunais:

$[\ldots]$

c) prover, na forma prevista nesta Constituição, os cargos de juiz de carreira da respectiva jurisdição.
} 
a sociedade carente almejava ${ }^{5}$ (RAMOS NETO, 2009, p. 6-7). Segundo Santos (2011, p. 25), o processo de redemocratização e o constitucionalismo emergente contribuíram para

aumentar as expectativas dos cidadãos de verem cumpridos os direitos e as garantias consignadas na Constituição, de tal forma que, a execução deficiente ou inexistente de muitas políticas sociais pode transformar-se num motivo de recurso aos tribunais.

Para Rodriguez (2013, p. 42-45), a cultura do favor, do clientelismo, arraigada na tradição da sociedade brasileira, fez efervescer a postura de privilégio, de concessão seletiva de direitos, tornando o Poder Judiciário assoberbado de demandas populares, levando-o a atuar em âmbitos carentes de efetividade, mormente após a promulgação da Constituição Federal de 1988.

Nesse contexto de redemocratização e constitucionalização de direitos, na medida em que os cidadãos veem abaladas suas expectativas de cumprimento das garantias fundamentais, mediante a omissão ou ineficiência das políticas sociais, tal panorama impulsiona a alternativa à seara judicial. Passa-se a fixar a ideia de que "é dever dos juízes e tribunais aplicar as leis em conformidade com os direitos fundamentais, além de 'colmatar' lacunas à luz das normas de direitos fundamentais" (STRECK, 2017, p. 244).

\subsection{Discricionariedade e criacionismo judicial}

Para Barroso (2001, p. 32-33), a inserção do constitucionalismo moderno como fundamento teórico de validade do Estado democrático de direito, além de promover a aproximação entre direito e ética, estimulou a dinâmica de valoração dos princípios e sua dimensão constitucional, redefinindo seus significados e a extensão de sua aplicabilidade,

\footnotetext{
${ }^{5}$ Nesse sentido, Ingeborg Maus dispõe em seu artigo "Judiciário como superego da sociedade" que as relações individuais têm perdido espaço em meio às transformações de massa, dificultando a formação de uma crítica autônoma. Relaciona este fato ao que denomina como um processo de "envelhecimento da psicanálise", dificultando a imposição do clássico modelo de superego. Assim, "A construção de uma consciência individual passa a ser determinada muito mais pelas diretrizes sociais do que pela intermediação da figura dominante do pai" (2000, p. 184), o que proporcionou a ascensão da dita "sociedade órfã". Nesse cenário, em meados do século XX, emerge o poder Judiciário, "no qual se reconhecem todas as características tradicionais da imagem do pai" (2000, p. 185). A figura paternalista assumida pelo Judiciário se assenta, portanto, em meio à carência dessa "sociedade órfă" que necessita de um novo modelo de superego.
} 
como a separação dos poderes, dignidade da pessoa humana, razoabilidade e reserva de justiça.

Entretanto, a problemática árida encontra seus entremeios associados aos limites da discricionariedade judicial para a concessão de direitos, tendo como fator impeditivo o criacionismo judicial. Em verdade, muito embora articulado com a nova arquitetura principiológica instaurada na ordem vigente, o constitucionalismo garante a atuação judicial pautada na aplicação da lei e da Constituição, buscando garantir a efetividade dos direitos positivados, e afastando-se de atitudes que conduzam a juízos decisionistas ou arbitrários.

STRECK (2012, p. 66-67) reflete acerca do crescimento desenfreado da aplicabilidade dos princípios, enquanto um criativo "conjunto de álibis teóricos" com a intenção de servirem como meta-regras, a serem utilizados na ausência da norma regulamentadora. Essa proliferação principiológica propicia a formação da "Jurisprudência dos Valores", que "se inscreve nos quadros do paradigma da subjetividade, em que os valores superam o próprio texto, que seria a ponta de um iceberg, estando os valores submersos, prontos para serem descobertos pelo intérprete” (STRECK, 2017, p. 229). Em verdade, há que se diferenciar a defesa de uma jurisdição constitucional mais efetiva de um ativismo judicial, de modo que a primeira se baseia na teoria da argumentação jurídica, buscando a ponderação de valores e caracterizando-se por um culto antidiscricionário e antirrelativista (STRECK, 2017, p. 230).

Esse "pan-principiologismo", segundo a definição de Streck, eleva o crescimento de standarts interpretativos, repercutindo na falta de critérios lógicos que possibilitem uma previsão segura e livre de decisionismos. O mesmo "pan-principiologismo faz com que - a pretexto de se estar aplicando princípios constitucionais - haja uma proliferação descontrolada de enunciados para resolver determinados problemas concretos, muitas vezes ao alvedrio da própria legalidade constitucional" (STRECK, apud TRINDADE, 2012, p. 118). Neste sentido, segundo Trindade (2012, p. 121-122):

Ocorre que, para concretizar os direitos fundamentais, conferiu-se aos juízes discricionariedade para invocar o justo contra a lei. E, assim, após muitos anos de luta contra o positivismo legalista, incorremos em outro equívoco: substituímos o juiz boca da lei pelo juiz que pondera princípios e que, portanto, decide conforme sua consciência, a partir de valorações de ordem subjetiva, passando, assim, de um mecanicismo na aplicação do direito para um decisionismo [...], que vem reforçado pela ideia de que a discricionariedade é algo natural à decisão judicial (grifos do autor). 
Para Dworkin (2011, p. 50-53), o conceito de poder discricionário parte do pressuposto da existência de padrões, estabelecidos por autoridades e definidores da amplitude das decisões, cuja interpretação reclama uma aplicação não mecânica, voltada ao uso da capacidade de julgar. Assim, esse poder discricionário, longe de significar uma ausência de limites, pondera que a eventual inexistência de padrões deva ser equilibrada a parâmetros de bom senso e equidade ${ }^{6}$.

Por outro lado, Dworkin (2011, p. 60) sustenta que o juiz deve manter uma deferência a certas doutrinas em favor da manutenção do status quo, como a da supremacia do Poder Legislativo e do precedente, de modo que os juízes "não têm liberdade para escolher entre os princípios e as políticas que constituem essas doutrinas - também neste caso, se eles fossem livres, nenhuma regra poderia ser considerada obrigatória”.

É neste cenário de fluidez principiológica que que se afigura a dimensão da modernidade líquida aclamada por Bauman ${ }^{7}$, a qual emerge em meio a essa desprotegida fronteira do que é ou não apropriado ao campo de atuação jurídica, onde o ativismo judicial permanece obscuro e ainda sem contornos rígidos definidos.

\section{LIMITES DEFINIDORES DO ATIVISMO JUDICIAL}

A produção jurídica inexoravelmente deriva das transformações sociais, e a postura do juiz caminha neste horizonte. As concepções tradicionais do direito tendem a se modificar, alterando padrões formais que embasaram uma dita "visão normativista", fruto das tradições liberais clássicas. Para Rodriguez (2013, p. 166-167), essa visão normativista não se mostra capaz de atender às novas expectativas e exigências do direito, mormente porque limita a autonomia jurídica e sua capacidade de entendimento multidirecional, restringindo o conceito

\footnotetext{
${ }^{6}$ Dworkin sustenta uma visão deontológica do direito, afirmando não haver caso sem regra que o regule, sendo tarefa do juiz descobrir quais direitos as partes detêm, aplicando-os. Richard Posner, em contraposição a Dworkin, defende o pragmatismo das decisões judiciais, buscando afastar as concepções de direito e moral: "o mundo que melhor descreve o juiz americano médio em todos os níveis de nossas hierarquias judiciais e produz a maior percepção de seu comportamento é 'pragmático'. Não é tudo o que resta após o legalismo, a atitude extrema e a compulsão à teoria abrangente que são rejeitados por serem inadequadamente descritivos do comportamento judicial" (2010, p. 230, tradução livre).

${ }^{7}$ Zygmund Bauman, sociólogo polonês, nascido em 19 de novembro de 1945, e falecido em 9 de janeiro de 2017, dedicou boa parte de sua obra à compreensão do momento atual vivido, o qual cunhou de "modernidade líquida", em notável crítica à pós-modernidade e às interfaces do capitalismo. Fonte consultada: <https://www.engwhere.com.br/empreiteiros/Filosofia-do-Seculo-XX.pdf\#page=38>. Acesso em: 30 jun. 2019.
} 
do "jurídico" a uma circunferência delimitada por um código definidor da "gramática do direito".

Nobre e Rodriguez (2011, p. 18) apontam que a complexidade que caracteriza as mudanças sociais torna cada mais vez mais árdua a tarefa da regulação, uma vez que eleva o nível de abstração das normas e causa um impacto negativo ao efetivo atendimento às pretensões concretas dos indivíduos. Como consequência, a norma vista em sua singularidade passa a não mais atender integralmente às exigências sociais, demandando um esforço interpretativo que viria em oposição ao império do formalismo das leis.

Por óbvio, torna-se cada vez mais desafiadora a regulação normativa das multifárias necessidades humanas surgidas ou reinventadas no mundo moderno. A noção abstrata do homem, derivada do liberalismo clássico, revela-se insuficiente para fundamentar o nível de proteção almejado, e essa reprodução das singularidades conduz a uma postura exegética do aplicador das leis, traduzida no desenvolvimento de suas ações nos casos concretos.

A consequente "revolta contra o formalismo" tornou abertas as veias da criatividade judiciária, buscando afastar elementos da lógica pura e mecânica do processo jurisdicional e enfatizando a voluntariedade, discricionariedade e escolha diante de um caso concreto, onde o juiz não se restringe mais à função declaratória e dedutivista do direito, sem exprimir as nuances de sua valoração pessoal. Cappelletti (1999, p. 33) afirma que não cabe mais ao juiz amparar-se unicamente na norma preestabelecida, como padrão de uma possível atuação "neutra", de modo que suas decisões passam a ser envolvidas por critérios metajurídicos, perpassando âmbitos pessoais, morais e políticos.

Rodriguez (2013, p. 113), por sua vez, assevera que, levando-se em consideração a necessidade do juiz em proferir uma decisão ao caso concreto, como vedação ao non liquet, tal decisão não significa o amparo a uma mera subsunção normativa, devendo prezar por uma nova roupagem de formalismo, não redutível à simples operação lógicoformal.

Para Dworkin (2011, p. 129), na ocorrência dos "casos difíceis", pode o magistrado criar um novo direito, porém agindo como delegado do poder legislativo, "promulgando as leis que, em sua opinião, os legisladores promulgariam caso se vissem diante do problema”, e dentro dos limites dos "argumentos de princípio", os quais "justificam uma decisão política, mostrando que a decisão respeita ou garante um direito de um indivíduo ou de um grupo" (DWORKIN, 2011, p. 129). 
Streck (2017, p. 329), ao discorrer acerca da delimitação conceitual entre os "easy cases" e "hard cases", afirma que os novos rumos da jurisdição constitucional propuseram uma hermenêutica preocupada em redefinir as significações dos textos jurídicos, tendo em vista a insuficiência da subsunção exegética e da aritmética lógica e formalista. Dessa forma, a interpretação jurídica passa a ser regulada através das teorias da argumentação, criando-se racionalidades discursivas, "estabelecendo previamente modos de operar diante da indeterminabilidade do Direito" (STRECK, 2017, p. 329), objetivando assim o alcance das melhores respostas.

Partindo-se dessa compreensão, a distinção entre os casos fáceis e difíceis emana da concepção de “que os primeiros seriam produtos de 'meras' deduções/subsunções, enquanto os segundos exigiriam a construção de uma racionalidade discursiva que assegurasse condições para uma universalização do processo de atribuição de sentido" (STRECK, 2017, p. 330).

No contexto do "Welfare State", a complexidade social oriunda do crescimento industrial e suas consequências econômicas, sociais e culturais, deu ensejo à denominada massificação da sociedade, culminando em demandas de proporções coletivas, que produziram efeitos no Legislativo, com a insurgência da "orgia das leis", , bem como no aparelho administrativo, cuja organização demandou uma estruturação capaz de contemplar e dar efetividade às inovações legislativas (CAPPELLETTI, 1999, p. 39-57). "Em virtude dessa radical transformação da sociedade tradicional numa sociedade de massas, comprimida num mundo globalizado, que ressaltam crescentes e mutantes valores tecnológicos, os valores alteraram-se, interesses de outra ordem afloraram e passaram a clamar por proteção" (MANCUSO, 2019, p. 101).

\footnotetext{
${ }^{8}$ Esta "fúria legislativa" é exposta por Mancuso (2011, p. 63-65) como consectária da nomocracia, uma tendência a resolução dos problemas sociais através da reprodução desenfreada de normas. Assim sendo, este caminho torna-se atraente, "porque pouco impactante e por servir em muitos casos para administrar o assunto, passando à coletividade a (falsa) percepção de que algo foi feito pela instância competente, impressão que todavia logo se esvai quando a população se dá conta de que a norma não bastou para 'resolver o problema', se é que ela já não o recrudesceu, na medida em que os destinatários logo passam a excogitar formas de burlar a norma ou de escapar a seus efeitos. São numerosos os exemplos: avançam os loteamentos clandestinos, inclusive às margens dos mananciais, sem embargo da massiva produção normativa repressora; aumenta o desmatamento, a despeito da incessante positivação de textos em matéria ambiental; a criminalidade se exacerba, apesar da tipificação de novos delitos e dos aumentos das penas e sanções de toda sorte, como se verifica, dentre outros casos, nos crimes ditos de colarinho branco e no tráfico de entorpecentes. Tal estado de coisas evidencia ser verdadeira a (desoladora) afirmação de Jean Cruet: 'Vê-se todos os dias a sociedade reformar a lei; nunca se viu a lei reformar a sociedade"” (p. 63, grifos do autor).
} 
E o que dizer do Judiciário? Sua atuação perpassa pela tênue linha divisória entre a judicialização e o ativismo judicial. No sistema brasileiro, a judicialização encontra amparo no modelo constitucional vigente, mormente através da constitucionalização abrangente das relações sociais, que trouxe para a Carta de 1988 matérias de cunhos diversos, cujo status constitucional passou a fundamentar sua reclamação jurídica.

Barroso (2008, p. 4) afirma que "a Carta brasileira é analítica, ambiciosa, desconfiada do legislador", e exemplifica com o direito de acesso ao ensino fundamental ou ao meio-ambiente equilibrado, os quais, uma vez constitucionalizados, tornam possível a judicialização de sua exigência, levando ao debate judicial sobre ações concretas ou políticas públicas.

Contudo, a normatividade prevista na Carta de 1988 foi apenas a "ponta do iceberg" (STRECK, 2017, p. 229), o ponto de partida para a discutida problemática da efetividade dos direitos nela propugnados. Confrontando-se a realidade com o texto escrito, nota-se, como afirma Rodriguez (2013, p. 35-36), que um dos pontos a serem considerados envolve a falta de regulamentação de muitos dispositivos programáticos, aliada à falta de iniciativa do Legislativo e Executivo. É desse modo que uma história brasileira que inclua como atores os poderes Legislativo, Executivo e Judiciário ainda está por ser escrita (2013, p. 46).

Nesta seara, o ativismo judicial tende a extrapolar o arranjo constitucional, consistindo "na recusa dos tribunais de se manterem dentro dos limites jurisdicionais estabelecidos para o exercício do poder a eles atribuídos pela Constituição (TRINDADE, 2012, p. 111). Trata-se, segundo Barroso (2008, p. 6), de um exercício deliberado e proativo, oriundo de retrações legislativas, de imposições de condutas ou de omissões do Poder Público.

Entretanto, essa tendência criacionista do juiz não fundamenta a plena discricionariedade, não inibe o seu dever de legitimar as decisões por meio da motivação e argumentação racional ${ }^{9}$, de modo que, "evidentemente, Direito não é política no sentido de

\footnotetext{
${ }^{9}$ Streck defende a necessidade de formação de um juízo de fundamentação, capaz de validar a intervenção judicial em matéria administrativa: "percebe-se, assim, que a atribuição de sentido do que pode (ou deve) receber a chancela da jurisdição constitucional carece (ainda), para utilizar os próprios pressupostos habermasianos, de um discurso de fundamentação prévio (discursos de validade), do qual se possa extrair os limites e as condições de possibilidade sobre a oportunidade (ou não) de lançar mão do direito constitucional por meio de um controle judicial de constitucionalidade apto para estabelecer, entre outras coisas: a) 'a clareza do direito e para a manutenção de uma ordem jurídica coerente'; b) a possibilidade de intervenção nos casos de 'zonas cinzentas que surgem entre legislação e aplicação do direito'; c) quais as situações permissivas de 'configuração criativa' da jurisdição constitucional” (2017, p. 239-240, grifo do autor).
} 
admitir escolhas livres, tendenciosas ou partidarizadas" (BARROSO, 2008, p. 14, grifo do autor).

Para Barroso (2008, p. 14), “mesmo nas situações que, em tese, comportam mais de uma solução plausível, o juiz deverá buscar a que seja mais correta, mais justa, à luz dos elementos do caso concreto". Neste sentido, a intervenção judicial - seja judicialização, seja ativismo - justifica-se diante da necessidade de conservação e promoção dos direitos fundamentais, buscando sanar uma omissão estatal, ou invalidar uma norma inconstitucional, cuja atuação se dá a favor, e não contra a democracia (BARROSO, 2008, p. 15; STRECK, 2017, p. 243-244).

Através dessa concepção, a atuação do juiz constitucional, enquanto protagonista do cenário jurídico-político, possibilita a superação de eventuais conotações "anti-heroicas", buscando a compatibilização de uma postura ativista à preservação da ordem democrática de direito. Nesse aporte, não se almeja, por outro lado, insculpir o julgador sob a roupagem de um "protagonista-herói”, um "Leviatã" da modernidade, mas como ator republicano e garante da justiça, contemplando um mundo de transformações de valores e novas necessidades.

\section{DISCRICIONARIEDADE ADMINISTRATIVA E O ARGUMENTO DAS CAPACIDADES INSTITUCIONAIS DO JUDICIÁRIO}

A discricionariedade administrativa pressupõe a capacidade do gestor público de mensuração e adoção do ato administrativo mais adequado à contemplação do fato que lhe é imposto, através da utilização da melhor técnica que esteja em seu domínio. Nessa linha, "o Estado se vale da expertise técnica da Administração para, v.g., definir que medicamentos utilizar para o tratamento da Aids, quais livros adotar no ensino básico público e como determinar a tecnologia a ser implantada na prestação dos serviços de telefonia" (ABRAHAM; CASTRO; FARIAS, 2016, p. 25).

À Administração Pública reconhece-se a gerência do mérito dos seus atos, cujas decisões perpassam pela análise da insindicabilidade judicial, dado o seu juízo de destinação ao interesse público. Quando o juiz pretende impor sua valoração pessoal, rompida está a discricionariedade administrativa, diversamente de uma atuação que visa combater atos administrativos praticados de modo desarrazoado e impróprio aos fins legais. Naquele caso, 
nota-se que o Judiciário excede sua competência originária, entrando em colisão com a teoria da dificuldade contramajoritária e incorrendo na problemática da politização da justiça ${ }^{10}$.

Por outro lado, o reconhecimento de que o direito está intrinsecamente ligado ao mundo dos fatos, torna-se uma questão contundente, de modo que o juiz necessita ter uma visão panorâmica acerca do caso concreto que lhe é posto. A mais justa decisão certamente não se embasará no tecnicismo da norma pura, na "gramática do direito"11, mas em uma análise transdisciplinar da situação fática, contextualizada à realidade multifacetada e agregadora de complexidades que se sobrepõem ao padrão decisório atinente à mera subsunção lógico-formal.

O garantismo encontrado na vastidão do texto constitucional de 1988 reforça este entendimento. Segundo Barroso (2008, p. 13), “a Constituição faz a interface entre o universo político e o jurídico, em um esforço para submeter o poder às categorias que mobilizam o Direito, como a justiça, a segurança e o bem-estar social”. Mancuso $(2011$, p. 88) atenta para a necessidade de se repensar o binômio judicialização da política/politização da Justiça, principalmente em face da opção feita pelo constituinte originário em estabelecer a democracia participativa como regime de governo, legitimando a representação da comunidade para o controle das condutas da Administração pública, de modo a culminar no recorrente caminho da judicialização.

Neste panorama, muitas questões judicializadas acabam permeando vieses metajurídicos e transdisciplinares, imbricando-se sob as órbitas políticas, sociais e/ou econômicas $^{12}$, reclamando do Judiciário uma cognoscibilidade pertinente, prima facie, ao poder Executivo. Mancuso (2011, p. 79) afirma que o Judiciário, por ser uma instância de sobreposição, detém a competência de intervir em controvérsias de largo espectro, mormente quando abrangem elementos provindos de outros campos do conhecimento, como a biologia, a ecologia, a medicina, a economia popular, a ordenação urbanística, etc. Assim:

\footnotetext{
${ }^{10}$ Representante dessa discussão é o dualismo existente entre os argumentos de princípio e argumentos de política (DWORKIN, 2011; RAMOS NETO, 2009; STRECK, 2017, p. 232), tendentes a justificar uma intervenção judicial. Quando o juiz penetra sob os afluxos de seu livre arbítrio, rompendo com a lógica da independência e harmonia entre os poderes, inegavelmente sua atitude vai além da argumentação principiológica amparada pelo ordenamento constitucional, descaminhando aos meandros da política.

${ }^{11}$ Cf. exposto no capítulo 3.

${ }^{12}$ A este respeito, Mancuso (2011, p. 45) cita a repercussão geral da questão constitucional, para fins de admissibilidade do recurso extraordinário no STF (art. 102, $\S 3^{\circ}$, da CF/1988), cuja transcendência exigida deve ser reconhecida quando presentes questões relevantes do ponto de vista econômico, político, social ou jurídico, que ultrapassem os interesses subjetivos da causa (art. 1.035, §1\%/CPC).
} 


\begin{abstract}
A se limitar a intervenção judicial às crises eminentemente jurídicas, não poderia a justiça determinar que o Sistema Único de Saúde arque com o custo de certa cirurgia a um paciente despossuído, porque aí a carência é de recursos financeiros; também não poderia uma decisão judicial dar respaldo à decisão da Administração Pública de vedar a realização de passeata de integrantes de certo segmento social numa dada via pública, porque aí se trata de um "problema social", conjugado com a política pública de uso da malha viária; igualmente, não poderia ser concedida liminar obstativa da construção de uma hidrelétrica numa área de preservação, porque o meio ambiente é de "uso comum de todos" (CF/1988, art. 225, caput), não se tratando, pois, de controvérsia entre sujeitos determinados (MANCUSO, 2011, p. 48).
\end{abstract}

Nesses arredores, exsurge o debate acerca da capacidade institucional do Judiciário para produzir decisões não ligadas às suas matérias de origem. Explica Barroso (2008, p. 16) que "temas envolvendo aspectos técnicos ou científicos de grande complexidade podem não ter no juiz de direito o árbitro mais qualificado, por falta de informação ou conhecimento específico". Assim, "em questões como demarcação de terras indígenas ou transposição de rios, em que tenha havido estudos técnicos e científicos adequados, a questão da capacidade institucional deve ser sopesada de maneira criteriosa" (BARROSO, 2008, p. 16).

$\mathrm{O}$ argumento das capacidades institucionais tem como palavra de ordem a especialização. Assim, no arranjo constitucional, coube a cada poder funções específicas que foram distribuídas conforme as melhores competências e conhecimentos técnicos que o tornam o mais habilitado para exercê-las. Cria-se, portanto, a presunção de que o poder constitucional "mais capacitado" tomará a decisão mais adequada diante de um caso concreto, excluindo, por conseguinte, eventual ingerência de outros poderes, órgãos ou instituições.

Arguelhes e Leal (2011, p. 16-17) advertem, contudo, que essa concepção de especialização é uma idealização, já que a realidade se mostra complexa e dinâmica e a alocação inicial de competências pode revelar-se cambiante entre os poderes, permitindo novas leituras a par das previsões constitucionais originárias. Embora assumam um papel importante na orientação acerca das matérias discutidas, as capacidades institucionais não são elementos estanques e não são infensas aos reclames sociais. A contestação e transformação do desenho institucional afigura-se como uma consequência inevitável das novas exigências apostas:

$\mathrm{O}$ argumento das capacidades institucionais se refere às habilidades e limitações de cada instituição para o exercício de suas funções em um cenário específico. Ele é considerado um pressuposto, à luz dos limites e capacidades do Poder Judiciário em si e em comparação com outras instituições, para a seleção de métodos de decisão mais apropriados nos quais juízes podem se orientar para interpretar textos e tomar 
decisões confiáveis. Funciona como critério para apreciar possíveis metodologias de tomada de decisão, e não como argumento de primeira-ordem voltado para criticar ou justificar decisões institucionais específicas. Pensar em capacidades institucionais significa, dessa forma, levar a sério as limitações e qualificações de uma determinada instituição no desenvolvimento de análises estáticas e dinâmicas relacionadas ao exercício de suas funções (ARGUELHES; LEAL, 2011, p. 40, grifos nossos).

Para Abraham et. al. (2016, p. 32-34), a avaliação mais justa deverá se dar no caso concreto, levando-se em consideração o órgão com maior aptidão para o pronunciamento definitivo. Assim, a nortear-se pelos elementos empíricos presentes na demanda, a melhor postura judicial nem sempre será aquela embasada no formalismo da autocontenção, mormente quando se eleva a pretensão à salvaguarda do mínimo existencial ${ }^{13}$, dos direitos fundamentais de minorias, e de normas constitucionais assecuratórias dos direitos básicos de saúde e educação.

O grande problema que desponta quando se permite ao Judiciário exercer uma capacidade institucional além das suas competências próprias, é a prática de eventuais excessos, desajustando o sistema de justiça, desequilibrando escalas coletivas de atendimentos e previsões orçamentárias, além de provocar possíveis soluções de continuidade em políticas públicas já implementadas. Isso notadamente ocorre quando juízes intervêm através de comandos cominatórios, estabelecendo exceções pontuais em prejuízo de uma demanda coletiva já planificada, com prévia alocação de recursos públicos.

É o que Barroso (2008, p. 16) aponta como “efeitos sistêmicos imprevisíveis e indesejados", de modo que as ações dos juízes, quando ausentes de adequada perícia, podem provocar impactos extra autos de dimensões incalculadas, em analogia ao efeito de uma pedra lançada sobre a água: “o ponto em que ela atinge a água é o efeito previsto e querido, mas, a partir daí se formam círculos concêntricos, que são efeitos quiçá não previstos, talvez mesmo não queridos, mas inevitáveis” (MANCUSO, 2011, p. 84). Para Barroso (2008, p. 17), “o Judiciário quase sempre pode, mas nem sempre deve interferir. Ter uma avaliação criteriosa da própria capacidade institucional e optar por não exercer o poder, em auto-limitação espontânea, antes eleva do que diminui”.

\footnotetext{
${ }^{13}$ Conforme Ingo Wolfgang Sarlet (2012, p. 411), "a garantia de proteção do núcleo essencial dos direitos fundamentais aponta para a parcela do conteúdo de um direito sem a qual ele perde a sua mínima eficácia, deixando, com isso, de ser reconhecível como um direito fundamental. [...] A ideia fundamental deste requisito é a de que existem conteúdos invioláveis dos direitos fundamentais que se reconduzem a posições mínimas indisponíveis às intervenções dos poderes estatais [...]".
} 
Por outro lado, Abraham et. al. (2016, p. 36-37), defendem a retirada do véu das capacidades institucionais do Judiciário, quando diante de comprovada ausência de prestação estatal, iminente à violação de direitos fundamentais:

\begin{abstract}
Cotejando as capacidades institucionais dos órgãos políticos e do Judiciário, verifica-se que os juízes possuem vantagem institucional quando o que está em jogo é a necessidade de garantir a efetividade dos direitos fundamentais. Esses direitos representam a positivação, no texto constitucional, dos valores mais básicos de uma determinada sociedade. Além disso, são condições essenciais para o funcionamento adequado do sistema democrático, sem os quais o processo político não atingiria padrões mínimos de isonomia participativa. Por essa razão, a defesa dos direitos fundamentais, inclusive dos direitos sociais, não deve ficar ao alvedrio das maiorias de plantão, cabendo ao Judiciário, sempre que se deparar com situações de omissão ou violação a estes direitos, garantir a sua plena efetividade (grifos nossos).
\end{abstract}

Estabelecer o justo sopesamento entre os limites e possibilidades de atuação do Judiciário, frente ao argumento das capacidades institucionais, é um desafio contemporâneo. Assim, conforme afirma Faria (apud Mancuso, 2011, p. 114), "à mercê de atos e serviços fora de sua jurisdição, este poder encontra-se assim numa encruzilhada".

\title{
4 CONSIDERAÇÕES FINAIS
}

A notória complexidade social vivenciada nos últimos anos proporcionou um amplo espectro de princípios, que passaram a servir de fundamentos de regulação judicial. Tem-se um novo conceito de jurisdição aberta, o qual não se propõe a servir de álibi para a formação de juízos decisionistas e arbitrários, mas como alternativa de derivação constitucional, fazendo com que os comandos constitucionais possam alcançar de fato os cidadãos, em sua máxima amplitude.

Com efeito, a visão normativista do direito tornou-se apática em meio às transformações propulsoras de novas leituras constitucionais, com um novo arranjo sistemático, que garante uma redistribuição ativa de competências em nome da construção maior da ordem jurídica justa. Essa "revolta contra o formalismo" motivou o Judiciário a alargar o seu campo de atuação, sobrelevando críticas acerca de um possível excesso de ativismo judicial.

Nessa órbita, só faz sentido falar em excesso de ativismo quando este passa a figurar como subterfúgio à formulação de escolhas livres, adentrando ao âmbito da discricionariedade 
administrativa. Quando o Judiciário atua enquanto um contrapoder viabilizador de direitos originariamente esquecidos, não se trata de ativismo, mas de favorecimento do equilíbrio da ordem jurídica, tomando o indivíduo como seu centro de proteção. "Ora, uma coisa é defender uma jurisdição constitucional efetiva, substancialista e republicana; outra coisa é aceitar decisionismos, muitas vezes - ou na maioria das vezes - feitos contra a própria Constituição [...]" (STRECK, 2017, p. 230, grifo do autor).

Assim sendo, cabe ao Judiciário viabilizar a justa satisfação dos programas sociais e das políticas públicas previstas pelo governo, reveladoras de direitos fundamentais, nos moldes cominados pela Constituição Federal. Nesse entorno, à luz do argumento das capacidades institucionais, questões de ordem social, técnica e econômica devem ser consideradas, e o juiz necessita ser amparado por subsídios provindos de outras esferas do conhecimento, a fim de formular uma decisão equânime, razoável e proporcional, sempre atenta à preservação do mínimo existencial.

Em verdade, a resposta justa e transdisciplinar que se almeja deve ser buscada no caso concreto, segundo a matéria tratada. Não se mostra razoável generalizar o manejo de um argumento que transpõe a órbita judicial. Assim como a dignidade humana, a cautela é imanente à garantia eficaz da ordem jurídica.

Verificada a possível repercussão de efeitos sistêmicos advindos do pronunciamento judicial, o tecnicismo argumentativo não deve ser visto de modo isolado e vinculante, capaz de justificar, por si só, a escolha do magistrado. Longe de ser uma ameaça à democracia, este balanceamento revela-se, acima de tudo, um levante à sua plena realização, proporcionando a transcendência da concepção de "microjustiça” para uma justiça de cunho social.

Eis uma discussão que ainda tende a propiciar futuros debates acadêmicos.

\section{REFERÊNCIAS}

ABRAHAM, Marcus; CASTRO, Diana; FARIAS, Edenilson Simas. Teoria das capacidades institucionais e reserva do possível no julgamento do $R E n^{\circ}$ 592.581-RS. Revista Controle: doutrinas e artigos, v. 14, n. 2, 2016, p. 18-51. Disponível em: <https://dialnet.unirioja.es/servlet/articulo?codigo=6167789>. Acesso em: 10 jun. 2019.

ARGUELHES, Diego Werneck; LEAL, Fernando. O argumento das “capacidades institucionais" entre a banalidade, a redundância e ao absurdo. Revista Direito, Estado e Sociedade, n. 38, jan./jun. 2011, p. 6-50. Disponível em:

<https://bibliotecadigital.fgv.br/dspace/handle/10438/24322>. Acesso em: 10 jun. 2019. 
BARROSO, Luís Roberto. Fundamentos filosóficos e teóricos do novo direito constitucional brasileiro. Revista da EMERJ, v. 04, n. 15, 2001, p. 11-47. Disponível em: < http://www.emerj.tjrj.jus.br/revistaemerj_online/edicoes/revista15/revista15_11.pdf>. Acesso em: 20 jun. 2019.

Judicialização, Ativismo Judicial e Legitimidade Democrática. Disponível em: < https://www.conjur.com.br/2008-dez-22/judicializacao_ativismo_legitimidade_democratica>. Acesso em: 20 ago. 2018.

BRASIL. [Constituição (1988)]. Constituição da República Federativa do Brasil. 24. ed. São Paulo: Saraiva, 2017.

BURGOS, Marcelo Baumann; SALLES, Paula Martins; VIANNA, Luiz WERNECK. Dezessete anos de judicialização da política. Cadernos CEDES, n. 08, dez. 2006. Centro de estudos de Direito e Sociedade - CEDES - IUPERJ: Rio de Janeiro, 2006.

CAPPELLETTI, Mauro. Juízes legisladores? Tradução de Carlos Alberto Alvaro de Oliveira. Porto Alegre: Sérgio Antonio Fabris Editor, 1999.

DWORKIN, Ronald. Levando os direitos a sério. 3. ed. São Paulo: Editora WMF Martins Fontes, 2010.

MANCUSO, Rodolfo de Camargo. Acesso à justiça - condicionantes legítimas e ilegítimas.

São Paulo: Editora Revista dos Tribunais, 2011.

. Interesses difusos: conceito e legitimação para agir. 9. ed. São Paulo: Thomson Reuters Brasil, 2019.

MAUS, Ingeborg. Judiciário como superego da sociedade. Novos estudos CEBRAP, n. 58, nov. 2000, p. 183-202. Disponível em: < http://www.direitocontemporaneo.com/wpcontent/uploads/2014/02/JUDICI\%C3\%81RIO-COMO-SUPEREGO-DASOCIEDADE.pdf>. Acesso em: 19 jun. 2019.

NOBRE, Marcos; RODRIGUEZ, José Rodrigo. "Judicialização da política”: déficits explicativos e bloqueios normativistas. Novos Estudos CEBRAP, ed. 91, v. 30, n. 3, nov. 2011, p. 5-20. Disponível em: <http://novosestudos.uol.com.br/produto/edicao-91/>. Acesso em: 19 jun. 2019.

OLIVEIRA, Odilon Cavallari de. O controle das finanças públicas à luz dos novos paradigmas de interpretação do direito. In: CIARLINI, Alvaro Luis de A. S. (org.). Temas de jurisdição constitucional e cidadania: linguagem, racionalidade e legitimidade das decisões judiciais. Brasília: Instituto Brasiliense de Direito Público - IDP, 2014, vol. 1.

POSNER, Richard. How judges think. First Harvard University Press paperback edition, 2010. 
RAMOS NETO, Newton Pereira. A construção do direito na jurisprudência do Supremo Tribunal Federal: limites e possibilidades no uso das sentenças aditivas. Observatório da jurisdição constitucional. Brasília: IDP, ano 2, 2008/2009.

RIBEIRO, Ana Gabriela Bahia. O fenômeno da judicialização da política no sistema constitucional brasileiro. In: Conpedi. Sociedade Global e seus impactos sobre o estudo e a efetividade do direito na contemporaneidade. São Paulo, 2013. Disponível em: <

http://www.publicadireito.com.br/artigos/?cod=6fb993285d56e692>. Acesso em: 15 ago. 2018.

RODRIGUEZ, José Rodrigo. Como decidem as Cortes? Para uma crítica do Direito (brasileiro). São Paulo: Fundação Getúlio Vargas, 2013.

SANTOS, Boaventura de Sousa. Para uma revolução democrática da justiça. 3. ed. São Paulo: Cortez, 2011.

SARLET, Ingo Wolfgang. A eficácia dos direitos fundamentais: uma teoria geral dos direitos fundamentais na perspectiva constitucional. 11 ed. Porto Alegre: Livraria do Advogado, 2012.

STRECK, Lenio Luiz. Neoconstitucionalismo, positivismo e pós-positivismo. In:

FERRAJOLI; Luigi; STRECK, Lenio Luiz; TRINDADE, André Karam (orgs.). Garantismo, hermenêutica e (neo)constitucionalismo: um debate com Luigi Ferrajoli. Porto Alegre:

Livraria do Advogado, 2012, p. 59-94.

. Verdade e consenso. 6. ed. São Paulo: Saraiva, 2017.

TRINDADE, André Karam. Garantismo versus neoconstitucionalismo: os desafios do protagonismo judicial em terrae brasilis. In: FERRAJOLI; Luigi; STRECK, Lenio Luiz; TRINDADE, André Karam (orgs.). Garantismo, hermenêutica e (neo)constitucionalismo: um debate com Luigi Ferrajoli. Porto Alegre: Livraria do Advogado, 2012, p. 95-131. 